\title{
Teología política y representación en el pensamiento de Carl Schmitt
}

\section{Political theology and Representation in Carl Schmitt's thinking}

\author{
Montserrat Herrero*
}

Universidade de Navarra, Pamplona, Espanha

\section{Resumen}

Cuando se habla de la teología política de Carl Schmitt, generalmente se hace referencia a la legitimación de la idea de soberanía como el vértice sobre el que gira toda la teoría del poder del jurista alemán. Esta identificación implica una concepción restringida de su idea de teología política, en la que más que un método viene a ser una teología política afirmativa, propositiva o prospectiva. Frente ese reduccionismo el artículo sugiere que además de diseñar un método de investigación como es la teología política, Schmitt desarrolló al menos cuatro teologías políticas, fundadas en cuatro tipos de analogía entre lo jurídico-político y lo teológico. Una de ellas es a la que podemos denominar "teología política de la representación política." La doctrina de la representación de Schmitt se funda en una analogía teológico política específica no reducible a la teología política del soberano, a saber, aquella entre la figura teológica del mediador, Cristo - y su representación terrena, la iglesia —, y la representación política. El artículo analiza

\footnotetext{
* MH: Doutora, e-mail: mherrero@unav.es
} 
las implicaciones de este tipo de teología política para una teoría de la representación política.

Palabras claves: Representación. Analogía. Teología política. Soberanía.

\section{Abstract}

When Carl Schmitt's political theology is mentioned, one generally alludes to the legitimation of the idea of sovereignty as the basis upon which lays his whole theory of power. This identification implies a restricted conception of his idea of political theology, which more than a method becomes an affirmative, proactive or prospective political theology. Before this reductionism, this paper suggests that in addition to political theology as a research method, Schmitt developed at least four political theologies, based on four kinds of analogy between the juridical-political and the theological. One of them is what we can call "political theology of political representation." Schmitt's doctrine of representation is based on a specific political theological analogy not reducible to the sovereign's political theology, namely, the one between the theological figure of the mediator, Christ (and his earthly representation, the Church), and political representation. Our paper analyzes the implications of this kind of political theology for a theory of political representation.

Keywords: Representation. Analogy. Political Theology. Sovereignty.

\section{Introducción ${ }^{1}$}

\section{Teología política y teologías políticas en la obra de Carl Schmitt}

Como ha defendido Herrero (2015 y 2017) Schmitt no solo descubre la capacidad heurística de la teología política como una matriz para la investigación en el ámbito de la historia de las ideas jurídicas o políticas, sino que escribe varias genealogías teológico-políticas. A

\footnotetext{
1 This article is part of the Project Las formas de representación del poder: ceremonias, juramentos y divisas founded by MINECO Plan Estatal de Investigación. Proyectos I+D Excelencia. HAR2014-58542-P. 2015-2017.
} 
pesar de la común asunción en la bibliografía (GALLI 1996; ULMEN, 1996; MEIER, 2009; DUSO, 2003; KALYVAS; 2008, ROBBINS, 2011; RAE, 2016) de que fundamentalmente la teología política de Schmitt es una teología política de la soberanía, tal como la expone en Politische Theologie, centrada en la decisión política, se pueden descubrir en su obra otras metáforas teológico-políticas diferentes de aquella entre Dios omnipotente y el soberano del Estado moderno. Pensar esta teología política como la única lleva consigo la casi inmediata identificación de la teología política con el decisionismo, que deja poco margen a una teoría de la representación que no sea autoritaria. Un caso paradigmático de esta interpretación es la tesis de Robbins (2011, p. 13) que habla del "lanzamiento antidemocrático de la teología política de Carl Schmitt." Sin embargo, como se verá más adelante, Schmitt estaría en desacuerdo con él puesto que la teología política no se traduce en un rechazo de la democracia. La teología política que vemos en Romischer Katholizismus, no es un caso particular o un desarrollo de la teología política de la soberanía.

La teología política es fundamentalmente un método de análisis histórico conceptual fecundo para la teoría política y jurídica que consiste, como Schmitt mismo señala en Politische Theologie, en una conceptualidad radical, es decir, en buscar la estructura última, la sistematicidad radical o la lógica estructural interna de los conceptos jurídico-políticos. Esto es lo que él entiende por "sociología de los conceptos jurídicos." No tiene, por tanto, que ver con la aplicación o derivación en la práctica política de doctrinas teológicas (ULMEN, 1996; HERRERO, 2015; DUSO, 2003; KAHN, 2011).

Sin embargo, Schmitt no solo genera un método de análisis fecundo para la historia de las ideas, sino que desarrolla a lo largo de sus obras, al menos cuatro derivaciones teológico-políticas: una teología política de la soberanía, una teología política de la representación, una teología política del katechon y una teología política de la revolución. Cada una de ellas está basada en una analogía teológica-política diferente. La primera, como ya hemos referido se fundamenta en la analogía entre la omnipotencia de Dios y el poder soberano; la segunda en la figura teológica del mediador, Cristo y su iglesia, y la representación 
política; la tercera en la figura bíblica del katechon y el verdadero poder político y finalmente la cuarta en la relación trinitaria y la relación política amigo- enemigo.

A través de la primera analogía, fundamentalmente desarrollada en Politische Theologie. Vier Kapitel zur Lehre von der Souveranität (Schmitt, 1922) Schmitt quiere poner de manifiesto la potencialidad de la decisión política en la construcción moderna del Estado. La analogía le ofrece la perspectiva adecuada para comprender al soberano como un poder supremo, legibus solutus, tal como Bodin lo caracteriza en los Six livres de la république y como Hobbes diseña su poder en Leviathan. El Estado moderno tiene como carácter específico lo absoluto de su poder y ese carácter se manifiesta fundamentalmente en la decisión ante la excepción - el caso que no se puede decidir según la ley -, como ocurre en el caso de la actuación divina en el milagro. Con perspectiva histórica podemos afirmar que en aquel momento nadie podía haber experimentado un poder tan grande. Si tanto Bodin como Hobbes pudieron imaginarlo fue gracias a la analogía teológico-política. Toda imagen posterior del estado moderno depende de esta construcción absolutista del poder, aunque se halle mitigada por el aparato legal en el moderno Estado de Derecho fundado en la doctrina kelseniana y su sabía construcción dual de poder constituyente y poder constituido, uno legitimante y otro legitimo. Pese a que esta analogía supone un modo de representación del poder en la teoría de la soberanía, Carl Schmitt no alude a ella para referirse al aspecto de la representación, sino fundamentalmente para describir el carácter del poder. Esta analogía, a partir de la cual Schmitt desarrolla su concepto metodológico de la teología política, había sido anticipada en otras obras de ese periodo juvenil. Es el caso de Politische Romantik (SCHMITT, 1919), donde encontramos una analogía entre el dios ocasionalista y deísta de Malebranche y la política romántica oportunista. Y también es el caso de Die Diktatur. Von den Anfängen des modernen Souveranitätsgedankens bis zum proletarischen Klassenkampf (SCHMITT, 1921) donde encontramos la transferencia significativa de la plenitudo potestatis papal a la praxis de los comisarios reales. En ambos casos se trata de una analogía entre el poder de Dios o de su representante y el poder del soberano 
similar a la que encontramos en Politische Theologie: cuando cambia el modo de concebir a Dios, cambia el modo de entender el poder. De alguna manera estas dos obras aparecen a posteriori casi como bocetos de la tesis definitiva sobre la teología política del soberano que expresará en Politische Theologie.

Pero de entre las narrativas teológico-políticas citadas sí hay una que hace específicamente referencia a la representación y es aquella desarrolla la analogía entre la figura teológica del mediador, Cristo, y su representación histórica, la iglesia católica, y la representación política.

\section{Teología política de la representación}

No es posible entender la idea de representación política que esboza Carl Schmitt en sus escritos más que desde la teología política. Así lo entiende también gran parte de la bibliografía (ULMEN, 1996, p. 14; GALLI 1996, p. 251; DUSO, 2003, p. 189). Sin embargo, dejan al margen la específica teología de la representación que aparece en Romischer Katolizismus. Siguiendo esta específica analogía teológico política Carl Schmitt escribió dos pequeños volúmenes: Die Sichtbarkeit der Kirche. Eine scholastische Erwägung (SCHMITT, 1917) y Römischer Katholizismus und politische Form (SCHMITT, 1923). Sobre todo en el segundo aparece la primera reflexión de Schmitt sobre la teoría de la representación años antes de su extenso comentario en Verfassungslehre (SCHMITT, 1928). Por la fecha y el contenido hay que suponer que es un comentario sobre el trasfondo de su crítica al parlamentarismo del mismo año (SCHMITT, 1923²) y consiguientemente está en pugna con la forma de representación parlamentaria (McCORMICK, 1999, p. 203; ULMEN, 1996, p. 12).

La teología política de la representación supone una analogía entre la representación jurídica de ambas instituciones, la iglesia y el Estado y en este sentido hay que considerarlo un ejemplo de teología política (ULMEN, 1996, p. 14). Pone de manifiesto por un lado, cómo la iglesia en su tarea de representar a Cristo en la historia (SCHMITT, 1996, p. 16) viene a ser la autentica heredera del espíritu jurídico 
romano (SCHMITT, 2000, p. 6) ; lo cual nos habla de la capacidad medieval para crear figuras representativas (SCHMITT, 2000, p. 23). En este caso la transferencia de sentido parece moverse inicialmente del ámbito civil al ámbito teológico y posteriormente al revés, en la medida que señala a la capacidad representativa de la iglesia como ejemplo para la representación política.

Aunque esta afirmación pueda resultar extraña, de hecho como Schmitt reconoce en Romischer Katholizismus, la historia no ha podido liberarse hasta nuestros días de un miedo casi irracional al incomprensible poder político del catolicismo (SCHMITT, 2000, p. 4). Schmitt pretende sintetizar en qué consiste y señala la gran capacidad de hacer alianzas con las más variopintas tendencias ideológicas. Se podría hablar hoy de una capacidad de coalición que muchos han podido interpretar como un oportunismo político : "No parece que haya contraposición alguna que ella no abarque." (SCHMITT, 2000, p. 8). Schmitt observa que la fuerza de representación de la iglesia le hace capaz de poder convivir con cualquier tipo de organización política y así lo ha hecho a través de los siglos. Los representantes en la iglesia no son meros funcionarios, sino personas que heredan su potestad en una cadena ininterrumpida desde el mismo Cristo. Hay una relación personal que viene de arriba y que desciende hasta los últimos eslabones de la cadena. La autenticidad de esa representación consiste en que el interior y el exterior en la acción de quien representa no pueden ser separados. En el caso de la iglesia el sentido interno consiste en personificar a Cristo (SCHMITT, 1917).

Como mostró Kantorowicz años después en su tratado teológico-político sobre la Edad Media (KANTOROWICZ, 1997) la doctrina teológica de la iglesia como cuerpo místico, cabeza del cual es Cristo, fue acogida por los juristas de la época Tudor alrededor de 1300 para consolidar la idea de un estado en el cual la cabeza es el rey. Los paralelos con la iglesia gravitaban entonces en torno a la idea del cuerpo y no de la persona. En el caso del Estado, a diferencia de la cabeza, el cuerpo no muere. La continuidad del cuerpo es una ficción que se genera por la intermediación de la doctrina teológica de la constitución eterna de la iglesia gracias a la inmortalidad de su cabeza. Aunque Schmitt no fuera consciente de la investigación histórica de 
Kantorowicz, que se publicó en 1957, treinta y cuatro años después del texto de Schmitt sobre el catolicismo, su intuición efectivamente fue que la transferencia desde la configuración teológica a la jurídica en la cuestión de la "incorporación" del Estado se hizo a costa de la “personificación” (BENTO, 2017) y, por eso, su representación carece de la autenticidad de la representación política, que como mostraría años después en Verfassungslehre, es existencial, al tiempo que simbólica y no meramente jurídica. Efectivamente, en comparación con la representación auténtica, la representación estatal viene a ser meramente técnico-instrumental. En el Estado, la relación personal desaparece y se convierte en algo meramente funcional: el funcionario no tiene que comprometer su interior. Para él es suficiente el actuar exteriormente como un servidor del Estado. Esta degeneración derivó ulteriormente en la crisis representativa del sistema parlamentario.

Es patente que Schmitt tiene nostalgia de una representación auténtica. Prefiere, como pone de manifiesto en ese mismo texto, la estética de la forma a la funcionalidad de la técnica. La idea de la representación política que Schmitt desarrollará fundamentalmente en Verfassungslehre se deriva de la analogía teológico-política con la representación de la iglesia católica. De ahí las notas características que atribuye a toda auténtica representación: mediación, visibilidad, publicidad, personalidad y definitivamente existencialidad.

\section{La representación como mediación}

Ulmen, en la introducción a la traducción inglesa que hace a Romischer Katholizismus señala que entre estos dos textos Schmitt hace la transición del concepto de mediación al de representación (ULMEN, 1996, p. 13). Efectivamente en Catolicismo no menciona el término mediación. Siempre sólo representación. Sin embargo en La visibilidad de la Iglesia, mediación es el concepto clave. Ulmen ve en eso el germen del proceso de secularización tanto de la iglesia como del pensamiento de Schmitt (ULMEN, 1996, p. 13). Sin embargo, el hecho de que posteriormente aparezcan ambas ideas intricadas en Verfassungslehre: 
"Representar es hacer perceptible y actualizar un ser imperceptible mediante un ser de presencia pública." (SCHMITT, 1934, p. 242) en mi opinión permite hacer una lectura conjunta de ambas obras, sin poner tanto énfasis en la discontinuidad de esos dos textos.

Efectivamente en Die Sichtbarkeit der Kirche señala la importancia de la mediación para la fe católica:

El verdadero cristiano no lo es por la impaciencia con que quiere llegar hasta Dios, sino por el camino que se propone para ello. Ese camino lo determina la ley de Dios; esto es el 'pan rema', lo que Cristo opone al tentador cuando éste le exige que convierta en pan las piedras. Su significado es el rechazo de la inmediatez, que quisiera saltar por encima del Mediador, de Cristo, y su instrumento, La Iglesia, para acallar el hambre de Dios (SCHMITT, 1996, p. 12).

La figura del mediador es central en la doctrina católica: Cristo, el Ungido, es esencialmente mediador entre el Padre y cada uno de los hombres. Eliminar la mediación ha sido desde el momento mismo de la encarnación del Verbo una tentación constante. Le mediación de Cristo no es cualquier tipo de mediación, como pudiera ser la de un profeta, sino una mediación divina. No sucede de abajo arriba, sino de arriba abajo. Lo superior desciende y arrastra con ello a lo inferior. Hay una elevación cualitativa: "la salvación consiste en que Dios se hace hombre y no en que el hombre se convierta en Dios" (SCHMITT 1996, p. 14). Como bien ve Galli (1996, p. 229) la representación política de la iglesia supone no la excepción, como ocurre con la doctrina de la soberanía, sino un exceso. El origen de su representación es un exceso. Como él dice, es una declinación del origen, en último término teológico-política, lateral y paralela a la decisionista de la soberanía que se funda no en el exceso, sino en la excepción (Galli 1996, p. 229).

El modo específico de esta mediación marca también el carácter de la iglesia: del mismo modo que el Verbo se encarna, es decir, aparece en la forma corporal, también la iglesia necesita de esa corporalidad aunque no en detrimento de la personalidad. Y, por eso, aunque su 
cabeza sea Cristo, ha de hacerse visible corporalmente en esta historia de los hombres. La corporalidad se la confiere la forma jurídica:

el tránsito al estado físico que lo religioso experimenta en lo eclesial, como el amor en el matrimonio, la concentración de lo pneumático en lo jurídico se ajusta al ritmo del surgimiento desde lo invisible de lo divino visible. Sin embargo, conserva siempre su unidad, del mismo modo que Dios siempre es uno. (SCHMITT 1996, p. 15).

La iglesia es descrita como triple gran forma: forma jurídica, forma estética y forma de poder (SCHMITT, 2000, p. 27). Schmitt insiste en que no es un mero corpus mysticum (SCHMITT, 1996, p. 14). Esto sería en su opinión una especie de sublimación espiritual congruente con una cristología en la que la encarnación histórica de Cristo se diluyera en una especie de eterno retorno del acontecimiento de Cristo en cada tiempo y ligar en la medida en que los hombres acogen en su corazón el hecho salvador. Más bien, sin embargo, la presencia de aquella mediación en el presente es tan histórica como lo fue el nacimiento de Cristo y corre cargo de la iglesia.

Del mismo modo, aquel que representa la unidad política no puede ser un mero mandatario, sino que por mediación de la decisión sobre el modo de ser de la unidad política de la que es capaz, es él la unidad política misma con una voluntad propia y no con la mistificada voluntad general del pueblo. Quien representa ha de conseguir unificar lo radicalmente diferente, ha de realizar la "conexión de los opuestos" y esto sólo es posible si se da alguna superioridad formal. Tanto el pensamiento antitético o dialéctico como el sintético es ajeno al modo de pensar católico: "con la Iglesia no congenia la desesperación de las antítesis ni el orgullo ilusionado de sus síntesis" (SCHMITT, 2000, p. 14). La iglesia tiene una racionalidad específica que radica en lo institucional, es decir, en la generación de realidades institucionales que permiten la cohabitación de las diferencias sin necesidad de anularlas.

Por otra parte, de la pura inmanencia de lo diferenciado no puede proceder ningún tipo de unidad de una comunidad, pero tanto la iglesia como el espacio específicamente político no son inteligibles sin alguna idea de unidad. Como él mismo indica, un espacio político que 
se quiera constituir al margen de la unidad sería redundante con el espacio mecánico-técnico o con el espacio económico que funcionan procesualmente según parámetros cuantitativos. En ese sentido, son aformes, como todo aquello que carece de un principio de unidad y tiende a la cosificación, como todo lo que carece de espíritu (SCHMITT, 2000, p. 25). Por eso: “es aquí, en el pensamiento económico, donde reside la oposición esencial de nuestro tiempo contra la idea política del catolicismo" (SCHMITT, 2000, p. 17).

Es justamente a diferencia del pensamiento económico por lo que la iglesia puede considerarse política de un modo eminente. Parece por ello congruente y no mero fruto de la casualidad histórica que la misma iglesia decidiera tomar la forma institucional del Estado, que a lo largo del XVII se hace cada vez más rígida, "como un carro blindado," dirá Schmitt. (SCHMITT, 2000, p. 20). Aunque no sólo puede ser considerada política por contraposición a lo económico, sino muy en particular porque posee un ethos de la convicción. Tener una idea rectora es parte de lo auténticamente político. Y la iglesia la tiene (SCHMITT, 2000, p. 21). Justamente eso es lo que le da su específica validez y autoridad: su idea no cambia, aunque se modifique, con los avatares históricos: "En la gran historia de la iglesia romana, junto al ethos de la justicia se encuentra también el del propio poder, que se enaltece hasta el ethos de la gloria, del resplandor y del honor" (SCHMITT, 2000, 40). Es un ethos de justicia porque representa al tribunal más allá del cual no hay apelación posible.

Schmitt transfiere al plano constitucional esta idea de mediación en Verfassungslehere. Ahí señala de nuevo cómo la representación política es principalmente una actividad de mediación. Esa actividad confiere personificación, visibilidad y publicidad a la unidad política (ADAM, 1992, p. 99). Estas mismas notas dan su carácter también a todo el ámbito de lo político (SCHMITT, 1928). Representa quien actúa en nombre del pueblo, quien habla por él.

En este punto aparecen resonancias de Hobbes en su Leviatán. Particularmente en la relación entre autor y actor: "la persona es el actor, y el dueño de las palabras y acciones es el autor" (HOBBES, 2006, XVI, p. 146). Tanto la persona natural como la política con actores; ahora bien, parece que el representante político no es autor más que como 
autorización. En la persona natural coincide la acción con la autoría, en la política, no (HERRERO, 2012). El que la representación suponga una sustitución de sujetos de acción, puesto que el actor no se identifica con el autor, es una novedad del concepto de representación hobbesiano. La persona o personas naturales, es decir, la representación, es la mediación entre el pueblo y el Estado, como autores, uno en sentido propio y otro representado, que se desdoblan imaginariamente como la realidad y la imagen en un espejo. Schmitt se mantiene en la idea clásica de que la capacidad de obrar requiere una persona natural, a diferencia de Hobbes, en cuya teoría la persona tiene un estatuto nominalista. Es una designación puramente exterior y no una propiedad interna de un ser (JAUME, 1986, p. 95). La persona en la cosmovisión hobbesiana solamente indica un fenómeno para un testigo. Es otro, quien designa como persona a algo que actúa. La construcción representativa proviene del exterior de quien representa. La representación, entendida de ese modo, que uno habla por otro, es decir, de una sustitución imaginaria de sujetos, es una de las grandes novedades teóricas de Hobbes, que la cultura política no ha abandonado hasta nuestros días. No es, sin embargo, el modelo que Schmitt ofrece. La representación no es resultado del pacto, sino que más bien lo trasciende en sentido jurídico e incluso puede antecederlo. La representación hace posible que un pueblo sea una unidad política y venga a ser poder constituyente. Es entonces cuando el pueblo pasa a estar en situación política y es a esa situación a la que Schmitt llama Estado, el cual puede adquirir diferentes formas según sea la propia conformación de la unidad política. No en vano el giro hobbesiano es considerado por Schmitt desde el punto de vista teológico político una "reforma acabada" (SCHMITT, 1965).

Parece claro, por tanto, que la actividad por la cual un "quién" es representante es la elevación de un pueblo a unidad política mediante una decisión por la cual el pueblo, ausente de modo positivo, pasa a estar presente políticamente. Una representación es legítima si es capaz, si tiene el poder, de mediar la decisión del pueblo, es decir de constituirlo. Por tanto, la legitimidad le viene de su función. Como señala Schmitt: "Sólo quien gobierna tiene parte en la representación" (SCHMITT, 1934, 
p. 245). Por eso sólo representa quien decide, quien puede tomar una decisión sobre el modo de existencia política de un pueblo.

\section{La representación como visibilidad}

La visibilidad de la iglesia, como he referido, aparece con la corporalidad jurídica, pero esto no tendría sentido fuera del hecho comunitario: "La gran traición que se reprocha a la iglesia romana es el no concebir a Cristo como un individuo privado ni al cristianismo como un asunto privado y pura intimidad, sino configurarlo como una institución visible" (SCHMITT, 2000, p. 40) La constitución comunitaria es esencial a la doctrina de Cristo. Sólo a través de la comunidad cada uno de los miembros puede relacionarse con Dios. El hombre no está solo en el mundo ni debe estarlo. Hay un mandato de comunidad en la esencia de su mensaje. La visibilidad de la iglesia se sustenta en algo invisible y lo invisible es también esta comunidad: "no hay iglesia invisible que no sea visible, ni tampoco iglesia visible que no sea invisible" (SCHMITT, 1996, p. 13). Pero una cosa es la "iglesia visible" y otra la "iglesia oficial." De alguna manera, lo que se ve de la iglesia invisible es la iglesia verdadera, "la auténtica iglesia visible"; algo que no siempre coincide con la iglesia "oficial," es decir, con la figura jurídica de la iglesia (FRANCO, 2009, p. 94). Por eso la iglesia ha podido conocer antipapas (SCHMITT, 1996, p. 14). De ahí que siempre subsista el mandamiento de obedecer a Dios antes que a los hombres. Como él sugiere, lo contrario sería una fuente de equívocos, mixtura de derecho y poder fáctico como la acontecida en el positivismo jurídico, tan criticado por él mismo. (SCHMITT, 1996, p. 15)

De nuevo esta idea de visibilidad es transferida al ámbito jurídico-político. Quien representa media entre el pueblo ausente y el pueblo presente políticamente, dirá en Verfassungslehre. Es decir, genera la visibilidad del pueblo. Realiza esa conversión a través de su acción. De ningún otro modo puede pasar el pueblo a ser una magnitud política. Ciertamente el pueblo está siempre presente potencialmente. $Y$, sin embargo, si no fuera por la representación quedaría como ausente de 
la decisión política. La actividad representativa saca al pueblo de su invisibilidad. Así dice: "Representar es hacer perceptible y actualizar un ser imperceptible mediante un ser de presencia pública" (SCHMITT, 1934, p. 241).

Lo característico de la representación es la dialéctica presenciaausencia. No es que el pueblo carezca de valor, sino que, por su propio modo de ser "negativo", aunque esté siempre presente potencialmente, ha de hacerse presente políticamente, es decir, actualmente presente. No puede entrar en la vida política sin una cierta elevación de su ser, sin una cierta unidad:

La dialéctica del concepto está en que se supone como presente lo imperceptible al mismo tiempo que se hace presente. Esto no es posible con cualquier especie de ser, sino que supone una particular especie de ser. Una cosa muerta desvalorizada o desprovista de valor, una cosa inferior, no puede ser representada. Le falta la superior especie de ser, que es susceptible de una elevación al ser público, de una existencia pública (SCHMITT, 1934, p. 241).

La dialéctica consiste en convertir al presupuesto invisible y ausente en un elemento políticamente visible y presente. En el acto de representar el representante se coloca en el lugar del pueblo y, en ese momento, el pueblo queda institucionalmente representado. Con la representación aparece la forma política. El caso particular de la soberanía, de hecho, viene abordado en Politische Theologie como problema de la forma política y de la decisión. Sobre todo en un lugar donde citando a Wolzendorf ratifica su definición del Estado como fuerza de un orden, forma para la vida de un pueblo. A partir de ahí, realiza Schmitt toda una tipología de la forma para detenerse a analizar la forma jurídica. Esta última nace porque la idea del derecho no puede transformarse a sí misma. Para convertirse en realidad efectiva, la idea del derecho ha de ser formada, se precisa de una transformación y, por tanto, de una "auctoritatis interpositio", de nuevo la idea de mediación (SCHMITT, 1922, p. 37-38; SCHMITT, 1934, p. 83).

La visibilidad que se adquiere no tiene que ver con el efecto de alguna causa, sino más bien supone una magnitud con un principio de 
unidad que no es completamente cuantificable o previsible. Lo propio de este tipo de forma es evocar una totalidad que es más que la suma de sus partes y que, por tanto, se forma de modo simbólico. La representación de un pueblo es más que aquello que puede expresarse por el resultado de un censo de población o por una suma de votos políticos.

\section{La representación como constitución de la publicidad}

En Romischer Katholizismus Schmitt expone con claridad la idea de publicidad que es característica de la institucionalización de la iglesia frente a toda la trama económica que se mueve en el ámbito de la privacidad. Escrita esta obra en el mismo año que Die geistesgeschichtliche Lage des heutigen Parlamentarismus, se puede considerar igual que ella como una obra antiliberal. La estructura jurídico-pública de la iglesia se opone a la fundamentación liberal de lo privado (SCHMITT, 2000, p. 35). Muy particularmente se opone a la privatización de la religión:

Históricamente considerada, la privatización empieza por el fundamento, por la religión. El primer derecho individual, en el sentido del ordenamiento social burgués fue la libertad religiosa; ésta constituye el comienzo y el principio motriz en el desarrollo histórico de derechos de libertad (SCHMITT, 2000, p. 35).

La iglesia representa lo antiliberal. No porque ella no preserve la no coacción religiosa, sino porque ella misma representa con su existencia el alcance público de la religión. Es en ese aspecto, como la institución política, eminentemente pública. Razonablemente, dirá Schmitt, en estricta analogía teológico-política una religión privada se convertirá en el correlato de una parlamentarismo que no puede generar más que un comercio de opiniones y votos que no es capaz de generar lo público (SCHMITT, 2000, p. 35).

Años más tarde, Verfassungslehre se hace eco de esta misma idea: "La representación no puede tener lugar más que en la esfera de lo público" (SCHMITT, 1934, p. 241). No es posible una representación que se desenvuelva en secreto, una representación que sea un asunto 
particular. La publicidad no es secreto, no tiene que ver con "actos apócrifos de soberanía". Frente a la dirección hacia el secreto que existe en todo poder, existe una contra dirección del poder hacia la publicidad (SCHMITT, 1968, p. 92).

En este punto hace una distinción entre dos sentidos del término representación que en el idioma alemán vienen diferenciados por dos palabras: Repräsentation y Vertretung (SCHMITT, 1923). La primera representación política - es diferente de la segunda - representación comercial (Selbstvertretung), cometido (Auftrag), etc -. Esta última pertenece por su naturaleza y origen al derecho civil y trata de contratos entre particulares. La representación política, sin embargo, no es un contrato porque no es un acuerdo de intereses entre particulares, sino el ejercicio público de un poder. Es del pueblo y para el pueblo. No es una relación de un individuo con otro, ni del pueblo con un particular. Y ello porque el representante, en cuanto tal, ha perdido su individualidad en favor de la publicidad y porque no son individuos los que son representados, sino el pueblo entero como colectividad. Ahora bien, hay que hacer aún un matiz y es que la verdadera representación sólo puede serlo de un pueblo públicamente formado y no de un pueblo que resulte de la suma diferenciada de los votantes, como es el caso del sistema parlamentario. Éste pretende considerar al pueblo en su totalidad física o natural (por oposición a existencial), para lo que no encuentra otro medio que la representación proporcional de intereses. La mayoría no es más, en ese modelo, que el producto resultante de una especie de "comercio de votos." Pero ahí - dirá Schmitt - no se halla reflejado todo el pueblo, sino sólo un conjunto de intereses privados. $\mathrm{Y}$, sin embargo, se usan indistintamente los términos parlamentarismo y “sistema representativo" (SCHMITT, 1990, p. 44). Representación significa en esta última expresión, representación razonable del pueblo en el parlamento. La pregunta es, ¿quién es entonces el representado? Grupos de intereses particulares del pueblo hallados numéricamente. Y a esto arguye Schmitt: "Aquello que sirve tan sólo a cosas privadas y a intereses privados, puede, es cierto, ser representado; puede encontrar sus agentes, abogados y exponentes, pero no será 'representado' en sentido específico" (SCHMITT, 1934, p. 243). 
En esa lógica no hay diferencia entre representante y representado porque se ha perdido el sentido de lo público. La acción de aquellos que forman el sistema representativo es también privada. En el marco de la actividad parlamentaria lo que se desenvuelve a la luz del día es una formalidad vacía y las decisiones verdaderamente importantes se toman de espaldas a lo público. Así el parlamento quizá pueda realizar funciones útiles, pero ha dejado de ser la representación de la unidad política del pueblo (SCHMITT, 1934, p. 241).

\section{La representación personal}

En Romischer Katholizismus Schmitt destaca la capacidad de la iglesia para generar figuras representativas como una herencia de su tradición medieval (SCHMITT, 2000, p. 23): es el caso del Papa, el sacerdote o el monje. Mientras que el Estado Moderno, como mucho ha creado la figura del legislador. Al tiempo que centra la atención en lo personal frente a toda cosificación, distiende temporalmente lo carismático que lleva consigo toda autoridad personal a través de la idea de "oficio," que se toma prestada del mundo civil, pero ni siquiera en ese caso se diluye el aspecto personal:

dado que el oficio se hace independiente del carisma, el sacerdote recibe una dignidad que aparece totalmente abstraída de su persona concreta. A pesar de ello, no es el funcionario o el comisario del pensamiento republicano y su dignidad no es tan impersonal como la del funcionario moderno, sino que su oficio se liga, en una cadena ininterrumpida, al encargo personal (SCHMITT, 2000, p. 17).

No tiene sentido la representación entre autómatas o máquinas. Ellos son sólo susceptibles de relaciones de causalidad. Sin embargo, este tipo de relación no es relevante ni en la representación que genera la iglesia, ni en la representación política. No es una representación cuantitativa, sino que en ella media la idea y, por tanto, es más bien simbólica. Así lo dice Schmitt: “De la gran representación se desprenden por sí mismos forma, figura y símbolo visible" (SCHMITT, 2000, p. 27). 
Esta idea es también transferida al ámbito constitucional. Quien representa es siempre una persona. El representante ha de ser un quién porque ha de ser capaz de obrar. No hay verdadera representación cuando el representante es generado técnicamente. Se trata de una imposibilidad física, pues para que un dispositivo tecnológico pudiera representar necesitaría de una persona física con capacidad de obrar. Schmitt lanza la idea de representación personal contra el liberalismo tecnológico (McCORMICK, 1997, p. 135).

Pero además, por ser persona, el representante encarna una dignidad personal. El pueblo, al ser representado, conserva su dignidad propia. Y, al tiempo, confiere un alto valor a la figura del representante, porque quien representa un alto valor no puede ser privado de él. En la representación, tanto el representante como el representado, adquieren una dignidad superior que supone un salto cualitativo. La presencia del pueblo, del principio de identidad como Schmitt lo denomina en la Verfassungslehre, es siempre necesaria como magnitud política para que la representación tenga lugar. Es justamente la "substanzielle Gleichartigkeit" (SCHMITT, 1921, p. 59; SCHMITT, 1990, p. 34; SCHMITT, 1934, p. 28) o la "Artgleichtichkeit" (SCHMITT, 1933, p. 8; SCHMITT, 19332, p. 42), el "modo de ser" del pueblo lo que viene a ser representado en toda auténtica representación. De ahí la existencialidad de la representación política que sólo puede ser encarnada en un quien y no sustituida por cualesquiera imágenes o mitos.

No es fácil, teniendo presentes estos textos y la importancia que Schmitt concede al nomos de la tierra, compartir totalmente - sí en parte la tesis de Kalyvas (KALYVAS, 2008, p. 121) cuando señala que Schmitt en el concepto de lo político trata de desesencializar la identidad política, en la medida en que la hace dependiente de la circunstancialidad de los conflictos políticos. Tampoco la de Franco que apoyada en una argumentación similar a la de Kalyvas habla del estatuto ficticio del pueblo político (2009, p. 395). Como señala Herrero (HERRERO, 2015) la "creatividad" de lo político para generar amigos y enemigos queda limitada por el nomos. Efectivamente los enemigos políticos no son "naturales," y sin embargo, la identidad política no es un elemento en continua mutación, ni una pura creación imaginaria con la que se pueda 
jugar arbitrariamente. La representación política es la explicitación "positiva" de una magnitud del poder que sólo puede ser definida en sí, negativamente: los que no ejercen funciones orgánicas de autoridad, los que no gobiernan, la multitud pluriforme, no organizada: "todos los que no son señalados o distinguidos, todos los que no se destacan por razón de propiedad, posición social o educación" (SCHMITT, 1934, p. 281). Y sin embargo no es completamente "sin cualidades."

Kelly pone de manifiesto hasta qué punto esta idea pudo estar influida en Schmitt por la idea de "tercer estado" de Sièyes (KELLY, 2004; KALYVAS, 2008). Efectivamente aparece en la analogía de Schmitt un claro potencial revolucionario en la medida en que tampoco Cristo desconoce la condición humana del hombre pecador, es decir, del hombre que reniega de su propia dignidad. Sin esa contradicción no se entiende la redención ni, por tanto, la naturaleza mediadora de la iglesia. De igual modo en el terreno político sin la contraposición de los principios político formales, identidad y representación, es posible llegar a comprender la representación. Al representante le viene la dignidad de la capacidad de elevación cualitativa de algo con una especial dignidad, el pueblo. Esta es una acción que sólo puede darse de arriba abajo y no al revés, porque no es posible que de un aumento de cantidad se consiga una superioridad formal. La coimplicación de materia y forma que delatan los principios político formales lleva consigo la coimplicación entre consenso y poder: “El auténtico poder produce auténtico consenso y el auténtico consenso produce auténtico poder. Sobre todo, un poder estable encuentra la más auténtica y segura aceptación del pueblo" (SCHMITT, 1958, p. 370).

Schmitt distingue entre Volksentscheid y Volksbegehren (SCHMITT, 1927). El acento de la distinción descansa en que puede existir una decisión del pueblo (Volksentscheid), que es ante legem y que, por tanto, se expresa al margen de los mecanismos constitucionales; y una decisión post legem (Volksbegehren), como es generalmente el referéndum, que sucede según los cauces previstos legalmente. La figura del representante no es un producto de un procedimiento legal para la formación del pueblo. Y esto es definitivo para la idea de la imposible sustitución de la personalidad de la representación por cualesquiera medios 
técnicos, incluso para la posibilidad de una democracia directa, que consistiera en la suma técnica de decisiones de individuos privados. Hasta tal punto Schmitt rechaza esta idea que llega a decir que:

la actividad propia, la capacidad y función del pueblo, el núcleo de toda expresión popular, el fenómeno originario y democrático, lo que también Rousseau vio como democracia en sentido estricto es la aclamación, el grito aprobatorio o condenatorio de la masa reunida [...] Ningún Estado sin pueblo, ningún pueblo sin aclamación. (SCHMITT, $1923^{2}$, p. 34).

La aclamación no es capitalizable cuantitativamente, pero sí personalmente. Es el representante quien explicita aquello que el pueblo en aclamación aprueba. Porque el pueblo no puede hablar con una sola voz se remite a una persona que sea capaz de discurso, de hacer a través de él visible la forma política. De ahí que en Romischer Katholizismus hable de la relación que siempre existe entre la capacidad para la forma y "la capacidad para crear el lenguaje de una gran retórica" (SCHMITT, 2000, p. 28).

Kalyvas ha señalado el valor de este aspecto de esta idea schmittiana como una reflexión significativa a la hora de abordar la incidencia de "lo extraordinario" en la creación del orden político, constitucional y simbólico, a través del concepto de poder constituyente (KALYVAS, 2008). Tanto él como McCormick y Scheuerman insisten en la importancia de este elemento para una teoría de la democracia, a pesar de lo insuficientes que resultan finalmente las tesis de Schmitt (KALYVAS, 2008; McCORMICK, 2009; SCHEUERMAN, 1999). Si bien McCormick y Scheuerman entienden que las deficiencias conducen finalmente a Schmitt a un planteamiento dictatorial (McCORMICK, 2009, p. 137; SCHEUERMAN, 1999, p. 81), Kalyvas en cambio deriva las tesis de Schmitt sobre la identidad política, en su combinación con el principio de representación, hacia una democracia constitucional. Ciertamente, dirá, en el momento extraordinario sólo es posible delegar el poder, sin embargo, la política normal necesita representación en la misma medida en que en un orden constitucional el pueblo se hace ausente y su soberanía invisible. Existe solamente de un modo simbólico a través 
de su representación política en el gobernante. En su opinión, gracias a esto, la teoría constitucional de Schmitt puede resolver las aporías del constitucionalismo liberal (KALYVAS, 2008, p. 128).

\section{Conclusión: representación existencial y simbólica}

Como se ve por lo dicho es imposible comprender el concepto de representación en el pensamiento de Carl Schmitt sin hacer referencia a su teología política. Incluso los análisis más jurídicos no pueden evitarlo (DOTTI, 2015, DUSO, 2003, KELLY, 2004, KALYVAS, 2008). Ahora bien, ninguno de los numeroros trabajos publicados sobre la cuestión de la representación establece una continuidad tan evidente como la que se ha tratado de enunciar aquí: la teoría schmittiana de la representación es un caso particular de una de las genealogías de su teología política.

Duso también señala que la representación pertenece al núcleo de la teología política de Carl Schmitt (2003, p. 175), pero la reconduce a una teología política de la soberanía (DUSO, 2003, p. 191). Sin embargo, como he intentado mostrar, no toda teoría representativa es una teoría de la soberanía. De hecho Schmitt se fija fundamentalmente en la iglesia como una figura medieval y el concepto de soberanía, con el carácter total y absoluto que adquiere en la pluma de Bodin y Hobbes, es un producto de la modernidad. Pero la modernidad no conoce, en su opinión, una auténtica representación en la medida en que ha sustituido la personificación por la "corporalización" estatal. La soberanía es, por tanto, un caso particular y poco auténtico, sea en su versión radicalmente democrática o radicalmente absolutista (SCHMITT, 1934, p. 273), de una teoría más general de la representación, que es la que él intenta esbozar.

Del examen teológico-político de las notas que Schmitt reserva a la representación, se puede concluir que, aunque la expresión jurídica de la representación sea esencial, su carácter último es existencial y, por eso, para ella la expresión jurídica no es suficiente, sino que al aspecto jurídico han de añadirse el simbólico; sea en términos de imagen o de metáfora.

Así lo dice en Verfassungslehre: la representación no es un fenómeno de carácter normativo, ni un procedimiento, sino algo de carácter 
existencial (SCHMITT, 1934, p. 242). La representación es pública, viene dada con el pueblo y participa de la misma realidad existencial que éste. Ahora bien, la existencia, con su carácter de vitalidad y totalidad no puede ser representada más que de modo simbólico y esto supone una superioridad formal. Como señala acertadamente Duso (2003, p. 194) lo que viene a decir la teología política de la representación es que toda auténtica representación requiere siempre de alguna fundación trascendente. Tempranamente la implicación de la transcendencia frente a la pura inmanencia de la modernidad política en la idea de representación de Schmitt había sido puesta de manifiesto por Przywara (PRZYWARA, 1958, p. 11). No deja de ser extraña la lectura antitrascendente que hace Rae (RAE, 2016) de Romischer Katholizismus como un mero alegato epistemológico sobre la importancia del elemento de fe sobre la razón en la decisión política, por muy loable que sea su explicación de la conciliación de la doctrina de la soberanía de Schmitt con su constitucionalismo. Justamente lo que admira Schmitt de la iglesia es su racionalidad, que se expresa del mejor modo en su condición de figura jurídica.

Si ahora vamos a su carácter simbólico, hay que decir que para la acción de representar lo que implica el símbolo es el sentido total evocado a través de decisiones concretas, que efectivamente en la medida en que son capaces de alumbrar una totalidad de sentido que no puede ser dicha con palabras o de cualquier otra forma, se convierten en simbólicas. El hecho de que la representación tenga carácter simbólico implica que lo más valorado de ella no es tanto la efectividad o adecuación de su actividad política, sino el hecho de hacerse foco de valores, actitudes, sentimientos, expresiones o acciones que se consideran apropiadas. En el fondo es la correspondencia con una idea y no tanto el rendimiento cualitativo lo que hace de la acción política un tipo de representación específica a diferencia de otro tipo de representación, que pueda estar más ligada a lo cuantitativo. Como señala Göhler la representación expresa simbólicamente valores compartidos que son fundamentales para la comunidad política y que no se pueden hacer presentes a través de un discurso o de una acción (GÖHLER, 2014, p. 23). Es la dificultad de Pitkin para concebir el símbolo integrado en la acción y en su forma, lo que hace que considere la representación simbólica como un elemento 
pasivo de la política, frente al hecho del gobierno y de la toma de decisiones que sería algo eminentemente activo (PITKIN, 214, p. 123-146). De ahí que entienda que los elementos simbólicos son meramente decorativos e irracionales: "el estático símbolo que suple" (PITKIN, p. 136).

La consideración de Schmitt se aviene en cierto sentido - salvando muchas distancias - a las características del poder simbólico que Bordieu resumía en su artículo sobre el poder simbólico de 1989: en primer lugar, la capacidad de crear una comunidad; si bien es cierto que en Bordieu aparece un aspecto dialéctico interno a la comunidad misma y, consiguientemente habla de grupo; mientras que en Schmitt ese aspecto dialéctico queda situado fuera de la comunidad. En segundo lugar, es un poder de revelación, de hacer visible algo que no lo era. La eficacia simbólica depende en su opinión del grado en el que la visión propuesta está fundada en la realidad (BORDIEU, 1989, p. 23). Vuelve a aparecer esa conexión entre poder simbólico y existencialidad.

Lo característico de la propuesta de Schmitt es la racionalidad o hiperracionalidad de lo simbólico que se genera en la capacidad de mediación. De alguna manera, como señala Kalyvas la representación simbólica remite siempre a lo extraordinario (KALYVAS, 2008, p. 7) y, por tanto, al momento fundacional del orden político en el que están implicados aspectos sustantivos, valorativos, a menudo invisibles y abstractos, del orden político (KALYVAS, 2008, p. 149). Siguiendo a Benjamin, McCormick denomina la posición de Schmitt un "concepto áureo de representación" frente a la representación cuantitativa y mecánica, (1999, p. 169).

Por mucho que esto pueda sonar a una teoría carismática de la legitimidad representativa al estilo weberiano (McCORMICK, 1999; EBERL, 1994; ULMEN, 1991) y, aunque Schmitt cite a Weber numerosas veces en su obra y particularmente en su Romischer Katholizismus, nada tiene que ver con ella. Sólo hay que mirar a un aspecto para quedar disuadido y es que en Weber el carisma es subjetivo, irracional y muy difícil de rutinizar. Sin embargo, Schmitt señala que la capacidad de representar viene de la idea superior que es un valor racional y es normativa, por tanto, se expresa en una gran forma jurídica. De hecho Schmitt ironiza de la legitimidad carismática weberiana como una derivación de la teología protestante, una deformación de una imagen 
teológica (SCHMITT, 1970, p. 41-42). Así Schmitt dice que lo que Weber escribe es una traducción del carisma de San Pablo y, sin embargo, carece de una auténtica legitimidad democrática en la medida en que ésta queda fusionada con la legitimidad legal. Kalyvas señala como, sin embargo, Schmitt aboga y promueve un principio democrático de legitimidad, basado en una teoría del poder constituyente del pueblo que es representado por el presidente solo ex ante, en tiempo de normalidad.

La teología política de la representación de Carl Schmitt se abre a las posibilidades de una teología política democrática, al contrario de lo que piensa la democracia radical, sin ser una teología política de la muerte de Dios, como lo es esta última. La teología política de la muerte de Dios no puede conceptualizar la representación, mientras que la teología política de la mediación de Cristo sí puede hacerlo, sin necesidad de derivar en una soberanía política de carácter autoritario. El error de la teología política de la democracia radical a la hora de hacer su crítica a Schmitt es no distinguir entre representación y soberanía por un lado $\mathrm{y}$, por otro, ver la teología política de Schmitt unívocamente orientada a una teología política de la soberanía (ROBBINS, 2011, p. 176). Sin duda la analogía que propone Robbins entre la multitud y el evento mesiánico funda otra teología política posible, pero cómo él mismo indica, no nos dice nada acerca de cómo podemos vivir políticamente (ROBBINS, 2011, p. 178). Ese es, probablemente, su potencial revolucionario.

\section{Referencias}

ADAM, A. Rekonstruktion des Politischen: Carl Schmitt und die Krise der Staatlichkeit, 1912-1933. Weiheim: V. C. H. Acta Humaniora, 1992.

BENTO, A. From the Medieval Church as a Mystical Body to the Modern State as a Mystical Person: Ernst Kantorowicz and Carl Schmitt. In: HERRERO, M. AURELL, J. Political Theology in Medieval and Early Modern Europe. Turnhout: Brepols, 2017.

BORDIEU, P. Social Space and Symbolic Power. Sociological Theory, vol. 7, n.1 pp. 14-25, 1989. 
DOTTI, J. E. La representación en Carl Schmitt. In: BUENO, R. Carl Schmitt Hoje. Politica, Dereito e Teologia. Sao Paulo: Max Limonad, 2015.

FRANCO DE SÁ, A. O poder pelo poder. Ficçao e ordem no combate de Carl Schmitt em torno do poder. Braga: Centro de Filosofía Universidade de Lisboa, 2009.

GALLI, C. Genealogia della politica. Carl Schmitt e la crisi del pensiero politico moderno. Bolonia: Il Mulino, 1996.

GÖHLER, G. Political Representation Reconsidered. In: DIEHL, P., ESCUDIER, A. La representation du politique: histoire, concepts, symbols. Les Cahiers du Cevipof 57, pp. 15-26, 2014.

DUSO, G. La rappresentanza politica: genesi e crisi del concetto. Milano: Franco Angeli, 2003.

EBERL, M. Die Legitimität der Moderne: Kulturkritik und Herrschaftskonzeption bei Max Weber und bei Carl Schmitt. Marburg: Tectum, 1994.

HERRERO, M. Ficciones politicas. El eco de Thomas Hobbes en el ocaso de la Modernidad. Madrid/Buenos Aires, Katz, 2012.

HERRERO, M. The Political Discourse of Carl Schmitt. A Mystic of Order. Lanham: Rowman \& Littlefield, 2015.

HERRERO, M. Carl Schmitt's Political Theology: The Magic of a Phrase. In: HERRERO, M. AURELL, J. Political Theology in Medieval and Early Modern Europe. Turnhout: Brepols, 2017.

HOBBES, T., Leviatán o la materia, forma o poder de un Estado eclesiástico y civil. Traducción, prólogo y notas de C. Mellizo. Madrid: Alianza, 2006.

JAUME, L. Hobbes et l'État représentatif moderne. PUF: París, 1986.

KAHN, P. Political Theology. Four New Chapters on the Concept of Sovereignty. New York : Columbia University Press, 2011.

KALYVAS, A. Democracy and the Politics of the Extraordinary. Max Weber, Carl Schmitt, and Hannah Arendt. New York : Cambridge University Press, 2008. 
KANTOROWICZ, E. H. The King's Two Bodies: A Study in Medieval Political Theology. Princeton University Press: Princeton,1997.

KELLY, D. Carl Schmit's Political Theory of Representation. Journal of the History of Ideas. v. 65, n. 1, p. 113-134, 2004.

McCORMICK, J. P. Carl Schmitt's critique of liberalism: against politics as technology. Cambridge: Cambridge University Press, 1999.

MEIER, H. Die Lehre Carl Schmitts. Vier Kapitel zur Unterscheidung Politischer Theologie un Politischer Philosophie. Stuttgart: Metzler, 2009.

PITKIN, H. F. El concepto de representación. Madrid: Centro de Estudios Políticos y Constitucionales, 2014.

PRZYWARA, E. Mensch. Nürnberg: Glock und Lutz, 1958.

RAE, G., The Problem of Political Foundations in Carl Schmitt and Emmanuel Levinas. London: Palgrave/Macmillan, 2016.

ROBBINS, J. W. Radical Democracy and Political Theology. New York, NY: Columbia University Press, 2011.

SCHEUERMAN, W. E. Carl Schmitt: The End of Law. Lanham, Md: Rowman \& Littlefield, 1999.

SCHMITT, C. Catolicismo y forma política. Traducción y estudio preliminar de Carlos Ruiz Miguel. Madrid: Tecnos, 2000.

SCHMITT, C. La visibilidad de la Iglesia. Traducción de Román García Pastor. Daimon. Revista de Filosofía, 13, p. 11-20, 1996.

SCHMITT, C. Sobre el Parlamen-tarismo. Madrid: Tecnos, 1990.

SCHMITT, C. Politische Theologie II. Legende von der Erledigung jeder Politischen Theologie. Duncker \& Humblot, Berlin, 1970.

SCHMITT, C. Nehmen, Teilen, Weiden. Ein Versuch, die Grundfragen jeder Sozial- und Wirtschaftsordnung vom nomos her richtig zu stellen. In: FORSTHOFF, E. Rechtsstaatlichkeit und Sozial-staatlichkeit, Band 118 Wege der Forschung, Darmstadt: Wissen-schaftliche Buchgesellschaft, 1968. p. 489-504. 
SCHMITT, C. Die vollendete Reformation. Bemerkungen und Hinweise zu neuen Leviathan Interpretationen. Der Staat 4, p. 51-69, 1965.

SCHMITT, C. Machtpositionen des modernen Staates. In: SCHMITT, C. Verfassungsrechtliche Aufsätze, Berlin: Duncker \& Humblot, 1958.

SCHMITT, C. Teoría de la Constitución, Revista de Derecho Privado, Madrid, 1934.

SCHMITT, C. Der Staat als Mechanismus bei Hobbes und Descartes. Archiv für Rechts- und Sozialphilosophie, Band 30, Heft 4, p. 622-632, 1937.

SCHMITT, C. Der Begriff des Politischen. Hamburg: Hanseatische Verlagsanstalt, 1933.

SCHMITT, C. Staat, Bewegung, Volk. Die Dreigliederung der politischen Einheit, Hamburg: Hanseatische Verlagsanstalt, 1933.

SCHMITT, C. Verfassungslehre. München/Leipzig: Duncker \& Humblot, 1928.

SCHMITT, C. Volksentscheid und Volksbegehren. Ein Beitrag zur Auslegung der Weimarer Verfassung und zur Lehre von der unmittelbaren Demokratie. Beiträge zum ausländischen öffentlichen Recht und Völkerrecht. Heft 2, p. 51-53, 1927.

SCHMITT, C. Römischer Katholizismus und politische Form. Hellerau: Jakob Hegner, 1923.

SCHMITT, C. Die geistesgeschichtliche Lage des heutigen Parlamentarismus, München/Leipzig: Duncker \& Humblot, $1923^{2}$.

SCHMITT, C. Politische Theologie. Vier Kapitel zur Lehre von der Souveranität. Berlin/München/Leipzig: Duncker \& Humblot, Berlin, 1922.

SCHMITT, C. Die Diktatur. Von den Anfängen des modernen Souveranitätsgedankens bis zum proletarischen Klassenkampf. München/Leipzig: Duncker \& Humblot, 1921.

SCHMITT, C. Politische Romantik. München/Leipzig: Duncker \& Humblot, 1919. 
SCHMITT, C. Die Sichtbarkeit der Kirche. Eine scholastische Erwägung. Summa. Eine Vierteljahresschrift, 2, p. 71-80, 1917.

ULMEN, G. Introduction to Roman Catholicism and Political Form. London, Westport (Connecticut): Greenwood Press, 1996.

ULMEN, G. Politischer Mehrwert: eine Studie über Max Weber und Carl Schmitt, V C H, Weiheim: Acta Humaniora, 1991.

Recibido: $27 / 04 / 2017$

Received: 04/27/2017

Aprobado: 24/06/2017

Approved: 06/24/2017 